\title{
An unusual case of right iliac fossa lump-spigelian hernia: a case report
}

\author{
Birma Ram $^{1 *}$, Manoj Gopinath', Saroj Chaudhary², Daisymol Johnson²
}

${ }^{1}$ Department of Radiodiagnosis, ${ }^{2}$ Department of Surgery, Command Hospital Kolkata (WB), India

Received: 10 September 2021

Revised: 06 October 2021

Accepted: 02 December 2021

*Correspondence:

Dr. Birma Ram,

E-mail: innovativehooda@yahoo.co.in

Copyright: ( $)$ the author(s), publisher and licensee Medip Academy. This is an open-access article distributed under the terms of the Creative Commons Attribution Non-Commercial License, which permits unrestricted non-commercial use, distribution, and reproduction in any medium, provided the original work is properly cited.

\begin{abstract}
Spigelian hernia is a relatively uncommon hernia of anterior abdominal wall, occurring in different anatomical tissue planes. It is a variant of inter-parietal hernia. Preoperative diagnosis of obstructed inter-parietal hernia is based on imaging. Once correctly diagnosed it is easily amenable to surgical repair. We present a case of Spigelian hernia presenting as right iliac fossa lump with features of small bowel obstruction.
\end{abstract}

Keywords: Spigelian hernia, intestinal obstruction, Ultrasonography, Computed tomography

\section{INTRODUCTION}

Spigelian hernia is a relatively uncommon hernia of anterior abdominal wall, occurring in different anatomical tissue planes. It is a variant of inter-parietal hernia. ${ }^{1}$ Clinical diagnosis of spigelian hernia is often challenging because most patients remain asymptomatic and anatomical location of the hernia which remains hidden in the anterior abdominal wall. ${ }^{2,3} \mathrm{We}$ present a case of Spigelian hernia presenting as right iliac fossa lump with features of small bowel obstruction. The patient was adequately investigated pre-operatively and surgically repaired without any post-operative complication.

\section{CASE REPORT}

A 53 years old female patient presented with history of pain in right iliac fossa and vomiting of 02 days duration associated with history of obstipation of 1 day duration. Further enquiry revealed that the pain in right iliac fossa was insidious in onset and gradually progressive in nature. It was associated with non-projectile vomiting and there was also history of not passing flatus or stool over the last 24 hours.
On physical examination her general condition was unremarkable, vitals were within normal range. Per abdomen palpation revealed tenderness in epigastric region and palpable lump measuring $15 \times 10 \mathrm{~cm}$ was noted in the right iliac fossa. Tenderness was noted overlying the lump. There was no guarding or rigidity. Bowel sounds were not perceived in the right iliac fossa.

Her lab investigation were all within normal range, haemoglobin was $10.1 \mathrm{gm} / \mathrm{dl}$, TLC 7370 cells/cmm. Other haematological and biochemical investigations were all within normal limits.

Radiograph of abdomen revealed gas filled small bowel loops (Figure 2), Ultrasound abdomen revealed dilated fluid filled small bowel loops without propulsive peristalsis. There was no free fluid in the abdomen. Subsequent CT scan confirmed the findings of USG and revealed a focal defect measuring approximately $3 \mathrm{~cm}$, in the right side of the abdominal wall through which ileal loops were seen herniating out into the parietes giving rise to the palpable lump. A diagnosis of small bowel obstruction at distal ileal level due to inter-parietal hernia was made. 


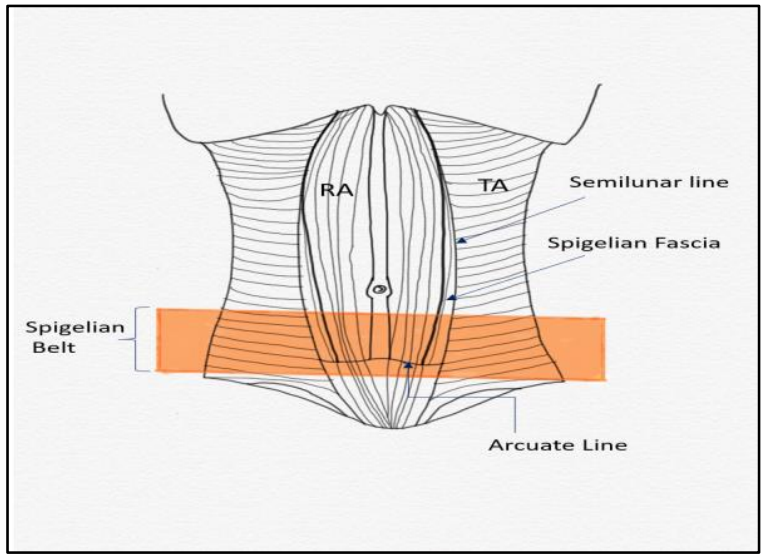

Figure 1: Anterior abdominal wall showing spigelian fascia. Spigelian hernia belt where spigelian fascia is widest $(6 \mathrm{~cm}$ area extending from umbilicus superiorly to the interspinous line joining two anterior superior iliac spine, inferiorly).

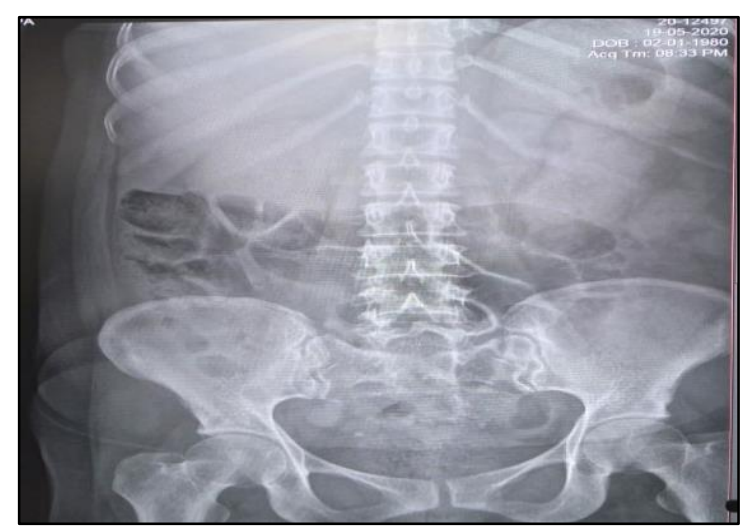

Figure 2: Abdominal radiograph suggestive of gas distended small bowel loops. No obvious air fluid levels are noted.

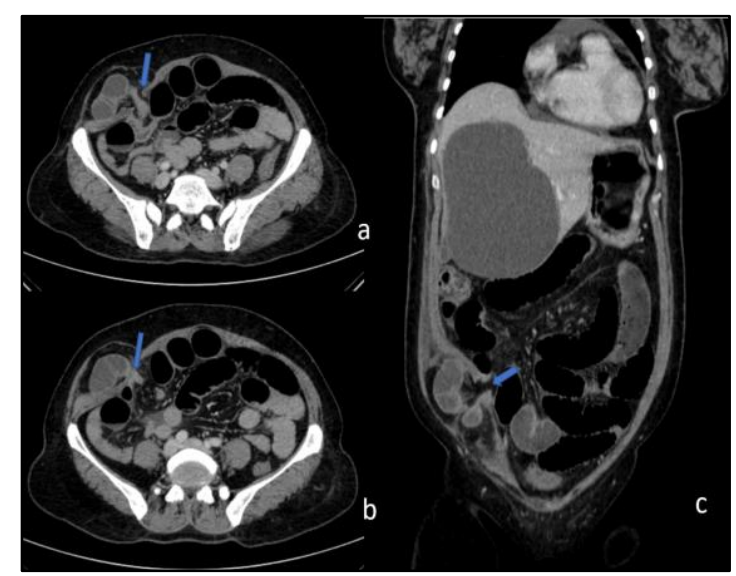

Figure 3: CECT abdomen (a, b) axial section and (c) coronal reformatted image showing defect in anterior abdominal wall (shown by arrow), bowel loops and omentum is seen herniating out, herniated contents are seen lying between the abdominal muscles and subcutaneous fat.

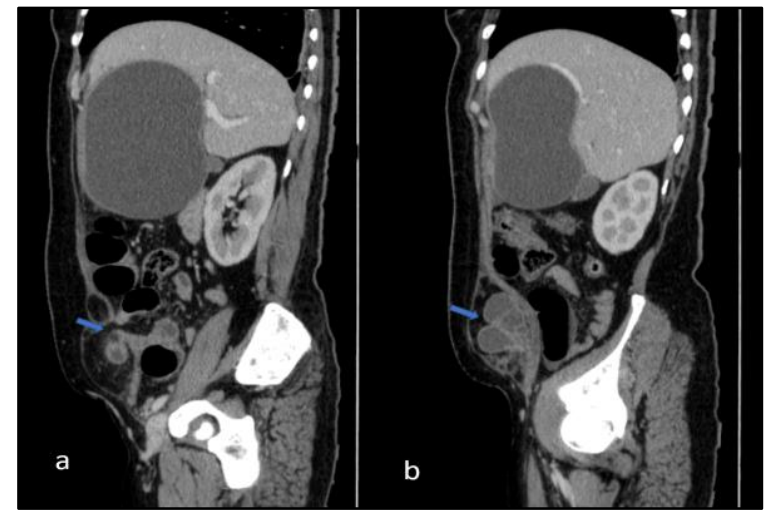

Figure 4: Sagittal reformatted images showing defect in anterior abdominal wall and hernial sac (shown by arrow).

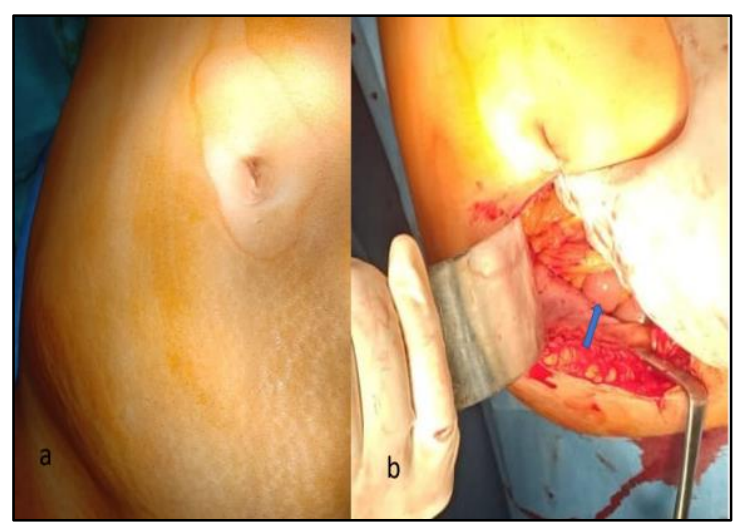

Figure 5: Pre-op (A) image showing contour bulge in right iliac fossa and intra -op $(B)$ bowel loop and peritoneal fat were found herniated through a defect in spigelian fascia.

The patient was taken up for urgent laparotomy. Surgical approach was made through lower midline incision. $3 \times 2$ $\mathrm{cm}$ defect was noticed in the transversus abdominus muscle and $6 \mathrm{~cm}$ ileal loops were seen herniated out through the defect. There was no evidence of discolouration of the bowel or any gangrenous bowel loops intra-operatively. The defect was repaired and mesh hernioplasty was done.

\section{DISCUSSION}

Hernia is the abnormal protrusion of a viscus or part of an organ through an abnormal opening in the wall of a cavity which contains it. Spigelian hernia is a variant of inter-parietal hernia. ${ }^{1}$ Spigelian hernia was first recognized by Josef Klinkosh in $1764 .^{2}$ The average diameter of the hernial ring usually ranges between 0.5 and $2 \mathrm{~cm} .{ }^{3}$ It occurs due to congenital or acquired defect of Spigelian fascia, located between the rectus abdominis muscle medially and the semilunar line laterally. (Figure 1) The external oblique fascia is generally intact. The hernia sac traverses between the internal oblique muscle and aponeurosis of the transversus abdominis muscle. ${ }^{4}$ 
The hernial sac contents can be omentum, mesenteric fat, small intestine or colon. ${ }^{4,5}$

The semilunar line or linea semilunaris extends between the 9th costal cartilage superiorly and the pubic tubercle inferiorly. It forms a border between the belly and aponeurosis of the internal oblique abdominal muscle. Spigelian fascia is composed of two different areas. ${ }^{6}$ The one, located below the umbilicus, is a combined aponeurosis of transverse abdominis muscle and internal oblique muscle aponeurosis. Above the umbilicus, the fibres cross and form a structure that prevents the hernia formation. Below the umbilicus, the fibres have a different direction and is a relatively weak area. The Spigelian hernia belt is widest and weakest, which extends from umbilicus and the line joining both anterior superior iliac spines. Approximately $90 \%$ of all Spigelian hernia cases occur in this area above inferior epigastric vessels.

Clinical diagnosis of spigelian hernia is often challenging because most patients remain asymptomatic, some may develop non-specific symptoms (like intermittent abdominal pain, swelling and occasionally acute abdomen) and anatomical location of the hernia which remains hidden in the anterior abdominal wall. ${ }^{6}$

Pre-operative imaging plays a pivotal role in diagnosing abdominal wall hernias. Computed tomography (CT) with or without contrast is investigation of choice for precise delineation of the defect and accurate identification of the contents of hernial sac. ${ }^{7} \mathrm{CT}$ scan helps to rule out other causes by excluding the presence or absence of tumor or appendiceal mass. ${ }^{7}$ Ultrasonography (USG) doesn't yield in definitive diagnosis due to tissue factor and operator dependence, yet it can aid in diagnosis. Light et al in their study reported that computed tomography (CT) had a sensitivity of $100 \%$ and a positive predictive value (PPV) of $100 \%$ whereas USG and Clinical assessment had a sensitivity of $90 \%$ and $100 \%$ respectively and a PPV of $100 \%$ and a PPV of $36 \%$ respectively. ${ }^{8}$

Differential diagnosis includes appendiceal mass, appendicitis, diverticulitis, spontaneous hematoma of the rectus sheath, abdominal wall lipoma, mass of the abdominal wall and ventral or inguinal hernia., ${ }^{8,9}$

Spigelian hernia has to be repaired because of a high risk of strangulation and incarceration especially in case of small defects. Asymptomatic cases, elective surgery can be attempted laparoscopically and increasingly advocated in elective Spigelian hernia repair, but open approach is appropriate in the emergency setting, particularly in the setting of small bowel obstruction, strangulation or incarceration where small bowel resection and anastomosis is indicated. Usually open surgery is the technique of choice and open "pre-peritoneal flat mesh technique" is employed to repair the defect. ${ }^{10}$

\section{CONCLUSION}

Inter-parietal hernias are uncommon hernias occurring at anterior abdominal wall at various anatomical (parietal) plains. Diagnosis should always be kept in mind as it can present as a case of intestinal obstruction of unknown origin. Preoperative diagnosis of obstructed inter-parietal hernia is based on imaging. Once correctly diagnosed it is easily amenable to surgical repair.

\section{Funding: No funding sources \\ Conflict of interest: None declared \\ Ethical approval: Not required}

\section{REFERENCES}

1. Sharma H, Rich L, Kelly MD. Spigelian hernia presenting as an appendicular mass. South Med J. 2007;100:1037-8.

2. Zaragoza C, Peiró F, Bebek H, Castaño S, Aguado RG, Vivó M et al. Spiegelian hernia: ambulatory surgical treatment. Ambulatory surgery. 2001;9(3):127-9.

3. Reddy KM, Stellakis ML, Khaliq T, Fiennes AG. Interparietal hernia mimicking malignant small bowel obstruction. Hernia. 1999;3(1):37-8.

4. Mittal T, Kumar V, Khullar R, Sharma A, Soni V, Baijal $M$ et al. Diagnosis and management of Spigelian hernia: A review of literature and our experience. Journal of minimal access surgery. 2008;4(4):95.

5. Hojer AM, Rygaard H, Jess P. CT in the diagnosis of abdominal wall hernias: a preliminary study. Eur Radiol. 1997;7(9):1416-8.

6. Truong SN, Jansen M. Diagnostic imaging in the evaluation and management of abdominal wall hernia. In: Fitzgibbons RJ, Greenburg AG (eds) Nyhus \& Condon's Hernia. Lippincott Williams \& Wilkins, Philadelphia. 2002;81-94.

7. Gungor B, Topgul K, Bilgin M, Malazgirt Z. Interparietal herniation: a rare cause of intestinal obstruction. Journal of Medical Cases. 2010;1(2):58-60.

8. Light D, Chattopadhyay D, Bawa S. Radiological and clinical examination in the diagnosis of Spigelian hernias. The Annals of The Royal College of Surgeons of England. 2013;95(2):98-100.

9. Toms AP, Dixon AK, Murphy JM, Jamieson NV. Illustrated review of new imaging techniques in the diagnosis of abdominal wall hernias. British journal of surgery. 1999;86(10):1243-9.

10. Zuvela M, Milicevic M, Galun D, Djuric-Stefanovic A, Bulajic P, Palibrk I. Spigelian hernia repair as a day-case procedure. Hernia. 2013;17(4):483-6.

Cite this article as: Ram B, Gopinath M, Chaudhary S, Johnson D. An unusual case of right iliac fossa lump-spigelian hernia: a case report. Int Surg J 2022;9:239-41. 